\title{
Risk Analysis of Cavitation in Hydraulic Structures
}

\author{
Gabriel Echávez \\ Engineering Faculty, National Autonomous University of Mexico, Mexico City, Mexico \\ Email: echavez@unam.mx
}

How to cite this paper: Echávez, G. (2021) Risk Analysis of Cavitation in Hydraulic Structures. World Journal of Engineering and Technology, 9, 614-623.

https://doi.org/10.4236/wjet.2021.93043

Received: June 2, 2021

Accepted: August 8, 2021

Published: August 11, 2021

Copyright (c) 2021 by author(s) and Scientific Research Publishing Inc. This work is licensed under the Creative Commons Attribution International License (CC BY 4.0).

http://creativecommons.org/licenses/by/4.0/

\begin{abstract}
Damages as a result of cavitation are ever existing problems in high-head spillways. This article presents a brief introduction to the problems associated with high-head spillways and describes a procedure that takes into account the flow near the chute surface where the phenomenon occurs, instead of the mean flow. Application of risk analysis methodology presented can be used to estimate whether there is a possibility of cavitation or there is necessity to determine where the first aereator should be located. The advantage of the procedure herein presented takes into consideration an important new variable, such as the surface roughness. In addition, emphasis should be placed first on the need to investigate other high-head dams which climate change may have exposed them to this kind of damages. Second, there is a need to make measurement in prototype. Finally, to underscore the importance of these problems, a comment is made concerning the Oroville Dam contingency in the state of California, (United States).
\end{abstract}

\section{Keywords}

Cavitation, Spillways, Damages, High Head, Risk Analysis, Surface Roughness

\section{Introduction}

Large reservoirs and hydraulic structures are common throughout the world, and they generally offer important benefits to the region or country where they are located. Therefore, there is a need for design, construction and maintenance to be taken into account since their particular characteristics may indicate new problems and issues. For example, in high-head dams, i.e. those that have heads higher than $80 \mathrm{~m}$, spillways release high-velocity flows and thus problems occur that are not found in smaller size dams. Damage induced by cavitation [1] [2] [3], is a wellknown problem globally. 
Air slots, perpendicular to the flow, placed in appropriate places in the spillway are used to protect the hydraulic works from this type of damages [4] [5] [6] [7]. Before now, a proposed study was conducted by Italians in the 1960s; however a new concept was later tested by countries like Russia, Venezuela, Brazil, United States, Colombia and Mexico. This concept has proven its effectiveness and has currently been assimilated into the usual design and construction process of these works.

The purpose of this paper is to present a procedure to find the zones in risk of damage due to cavitation that takes into account the flow near the chute surface where the phenomenon occurs, instead of the usual mean flow. This however has an advantage that it takes into consideration such as the roughness of the surface which can be useful for the designer. In addition, emphasis is placed first on the need to investigate other high-head dams with climate change, which are recently exposed to this kind of damages. Second, the need to make measurements in prototype because of the new available software, it is then necessary to work with more dependable real values.

In this work, the author used estimates based mainly on two well-known photographs of the damages that occurred in the Oroville dam, in the state of California (US), to emphasize on the importance and the current issues relating to this problem. The damages that occurred in the Oroville dam as a reference, clearly showed how the location and the form of the initial damage can be used to justify the author's opinion that the problem was initiated with cavitation.

The main objective of this study is to present a procedure to estimate the exposed areas to cavitation that takes into account the surface roughness [8] [9] [10], and the flow conditions near the floor and walls of the spillway [11], rather than the usually used mean flow [12] [13]. The procedure has been calibrated and validated with observations and data from several dams, which are already in operation with measurements of the water velocity close to the floor of the chute, which reveals the importance of measurements in prototype.

Another important objective of this work is to emphasize the need to check those high-head dams that are at risk of this kind of damage, because with the increase of precipitation associated to climate change; it is still possible to take steps in avoiding this preventable damage.

Finally, the contingency in 2017 at Oroville Dam in the state of California (US), which may have been originated by cavitation, is given as an example of this type of preventable situation.

\section{Methodology}

In any hydraulic work, a thorough risk analysis of cavitation is required to separately consider three characteristics, namely:

Spillway layout:

Misalignments: To be found in the transitions of the sections that change from rectangular to circular-which occur in tunnel spillways or due to misaligned slid- 
ing forms, and Surface irregularities such as protruding bars, ledges, concrete imperfections and scratches, does the spillway have a good finish?

The cavitation index used to estimate the occurrence of cavitation is given by the cavitation number or Thoma number. A lower index number simply means that velocity will be higher and pressure will be lower, setting the conditions for higher risk. For a hydraulic structure in operation, the index is calculated throughout the structure and results are compared with an inception cavitation index, that depends on the general characteristics of the spillway, the finishes in the zones in contact with the high velocity water and in how conservative this value must be; based on laboratory experiments, references and mainly prototype observations.

In those cases, the index calculated along the spillway surface for a given discharge, is lower than the chosen inception cavitation index, and there is a risk of cavitation induced damages, which will be progressive and may cause serious damages. Subsequently, each of the aspects mentioned above that has the tendency to affect cavitation is reviewed:

\section{Spillway layout:}

The general layout of the spillway is very important. In the convex vertical curves, the pressure reduction in the flow will significantly increase the onset of cavitation, whereas in the concave curves, the substantial increase in pressure will reduce this possibility and will overcome the effect of the reduction in the boundary layer height. In the horizontal curves, the flow depth in each section needs to be taken into consideration.

Misalignments:

This problem can be reduced by thoroughness in construction procedures, placing special attention to well-aligned forms and no existing steps or changes in direction. Figure 1 shows the characteristic damages caused in the $13 \mathrm{~m}$ in diameter tunnels by misalignment in Infiernillo Dam in Mexico, just after several days in operation in October 1965.

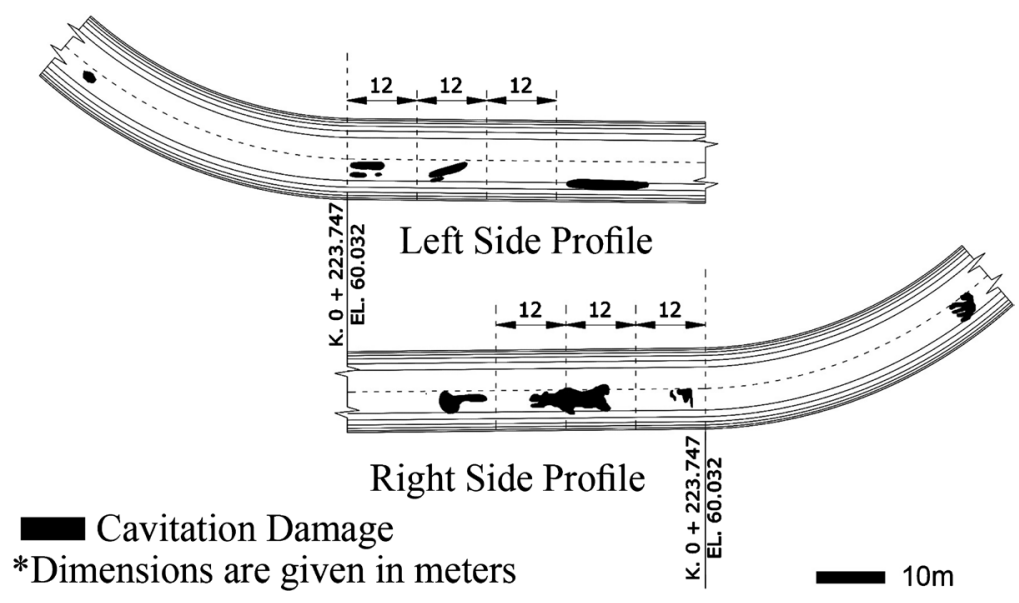

Figure 1. Misalignment induced damages on both sides of the $13 \mathrm{~m}$ diameter tunnel of Infiernillo Dam in Michoacan, Mexico. 
Surface irregularities:

Any protuberance over a smooth or rough surface may initiate erosion due to cavitation. The roughness of the surface can be represented by the Nikuradse, $k$, or the Manning, $\mathrm{n}$, and the calculation procedure must take into account both surface irregularities and the velocity of water near them, i.e., within the boundary layer-which increases as the fluid moves downstream-rather than the mean velocity that is usually used. Note worthily, it is necessary to keep a thorough inspection of the zones considered at risk of cavitation, and to do necessary maintenance at least once in a year to avoid this problem. Moreover, a proposed procedure is shown as an example as follows:

In a spillway in a circular tunnel as shown below in Figure 2, the cavitation index, $\sigma$, is calculated using the well-known formula included on the right side of this figure [11].

$h_{p} \quad$ pressure head in the surface,

$h_{V} \quad$ vapor pressure,

$V_{k} \quad$ water velocity at a distance $\mathrm{k}$ from the spillway surface, which is justified by the experimental points from diverse authors in a very wide range of roughness shown in Figure 3, and which follow the adjusted conservative curve of Equation (1).

$$
\frac{V_{k}}{\sqrt{2 g h}}=\frac{1.68}{0.33+\log x / k}
$$

Shown in the same figure.

g gravity,

$h$ vertical distance, measured from the free surface of the basin to the surface of the water in the section analyzed,

$k$ Nikuradse $k$,

$x$ distance from the spillway crest to the point of analysis.

In Figure 3, two important points were obtained by [14] and the other was measured in the Aguamilpa Dam, Nayarit, Mexico, because both were measured in prototype. In Aguamilpa, a Prandtl's tubes comb, $16 \mathrm{~cm}$ high, with four legs, as shown in Figure 4, was used.

As it can be seen in Figure 5, the water velocity close to the surface, which

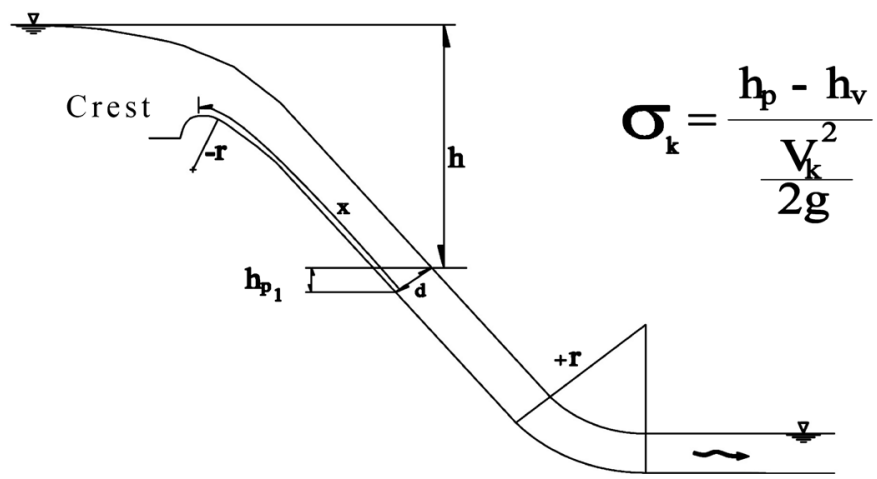

Figure 2. Spillway profile and variables identification. 


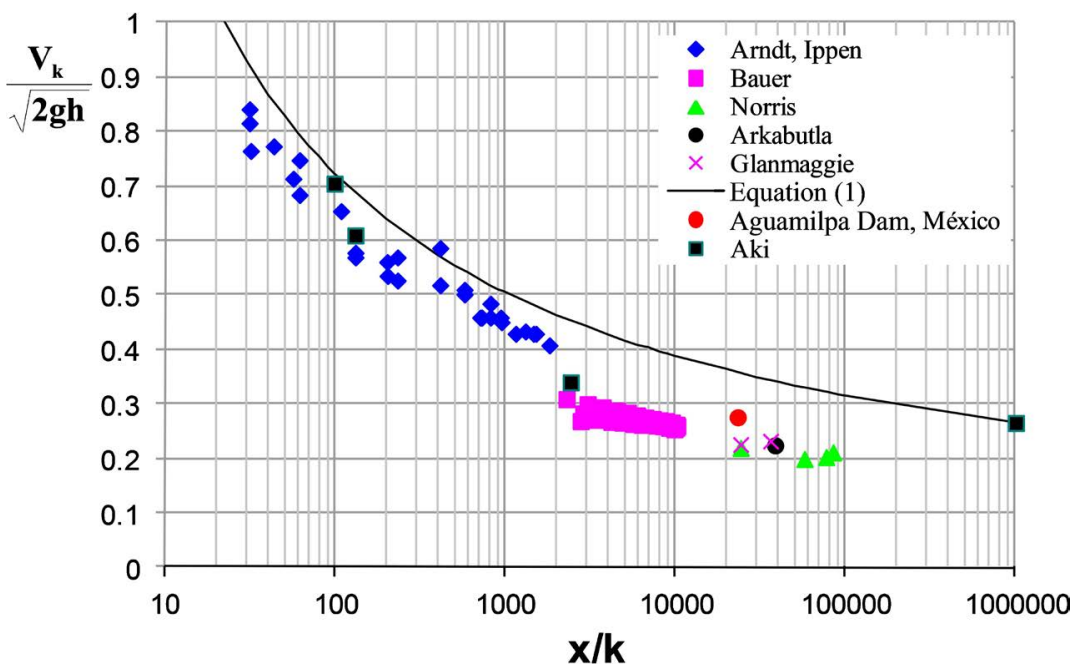

Figure 3. Results of using the surface irregularities equation.

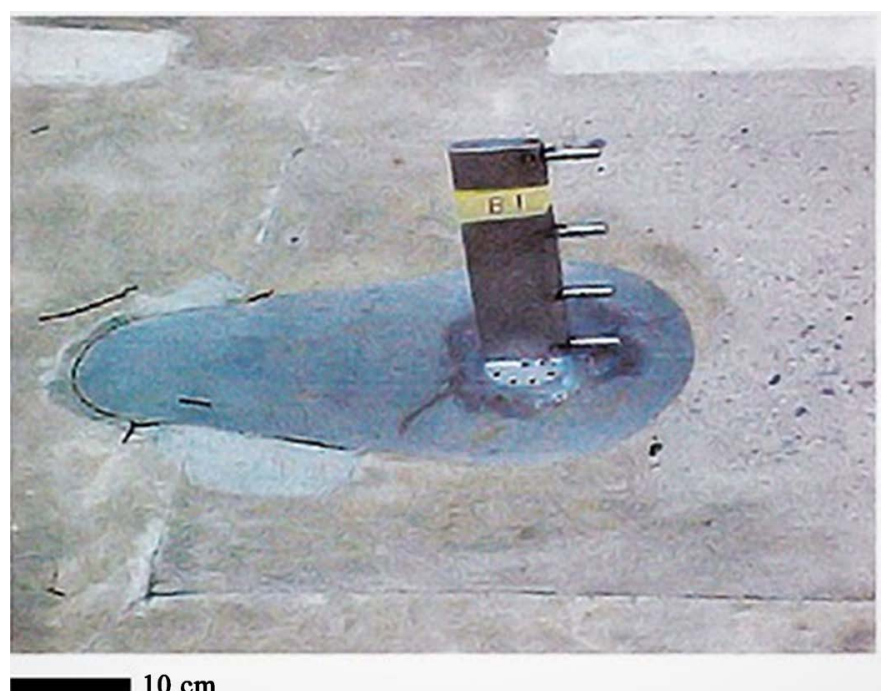

Figure 4. Prandtl's tubes comb, $16 \mathrm{~cm}$ high, placed on the spillway.

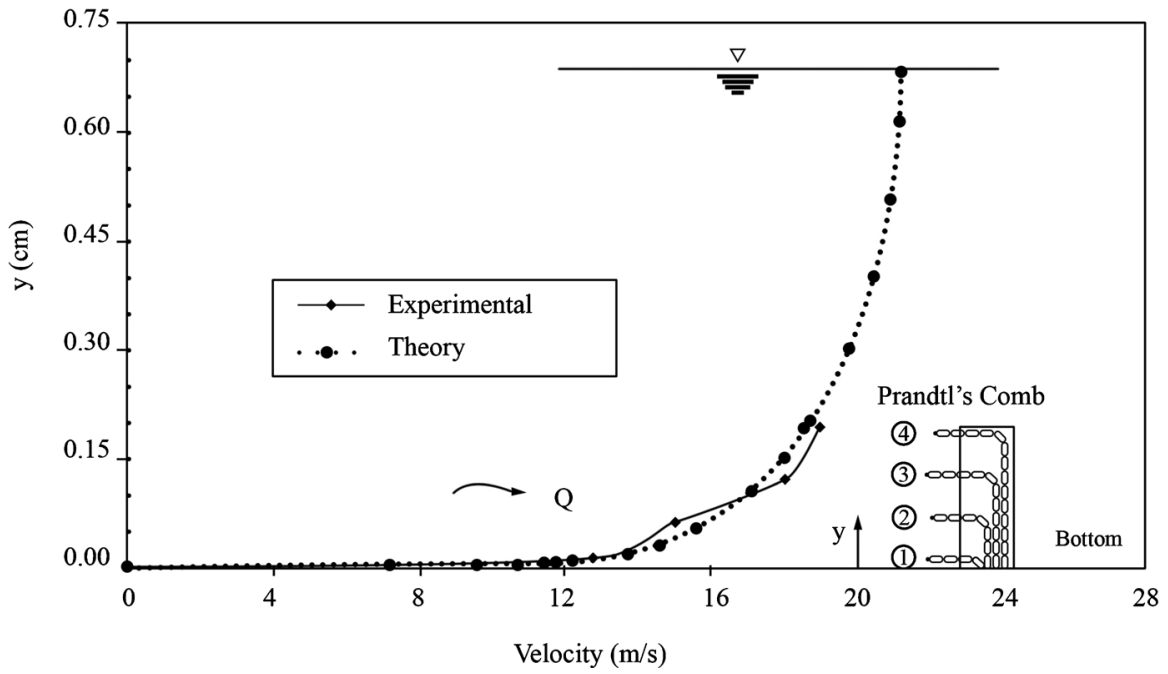

Figure 5.Velocity profile measured in prototype. 
depends on various factors, is very different to the mean velocity usually used in practice.

\section{Results}

\section{Application example:}

Analysis for a spillway in tunnel is presented to illustrate the procedure. The geometry for a circular tunnel spillway with a $13 \mathrm{~m}$ diameter is shown in Figure 6.

The considered roughness of the surface was $k=5 \mathrm{~mm}(n=0.017)$, and a discharge of $2500 \mathrm{~m}^{3} / \mathrm{s}$, was analyzed.

The cavitation index along the floor of the tunnel through water depths and floor pressures was obtained analytically and the check in model was calculated with the profile of the spillway for a given discharge. Thereafter, it was compared to an inception cavitation index (equal to 1.5 in this case).

As shown in Table 1 and the last but one column, in the station $180 \mathrm{~m}$, the cavitation index, calculated with the velocity $V_{k}$ given by Equation (1), is lower than the chosen inception cavitation index of 1.5, and thus, damages between the stations $160 \mathrm{~m}$ and $200 \mathrm{~m}$ can probably be expected. Therefore, it is recommended to protect this zone.

Furthermore, a procedural illustration results are shown in Figure 7 and Figure 8. The analyses applied were to the main and the emergency spillways of the Malpaso Dam, Chiapas, Mexico.

Emergency spillway: In contrast, as shown in Figure 8, there is no point along the emergency spillway that showed cavitation risk; this may sound ironic but the emergency spillway was safer than the control spillway in terms of cavitation induced damages.

In the risk zone, cavitation damages will not always occur and it can be protected with small discharges which are not usually used in the normal operation of the spillways, or with a very careful maintenance procedure in order to keep the zone without any protuberance, since any small protuberance over the general chute surface, even as small as one centimeter or even a lesser size, can initiate the erosion and start the chain reaction that will lead to serious damage.

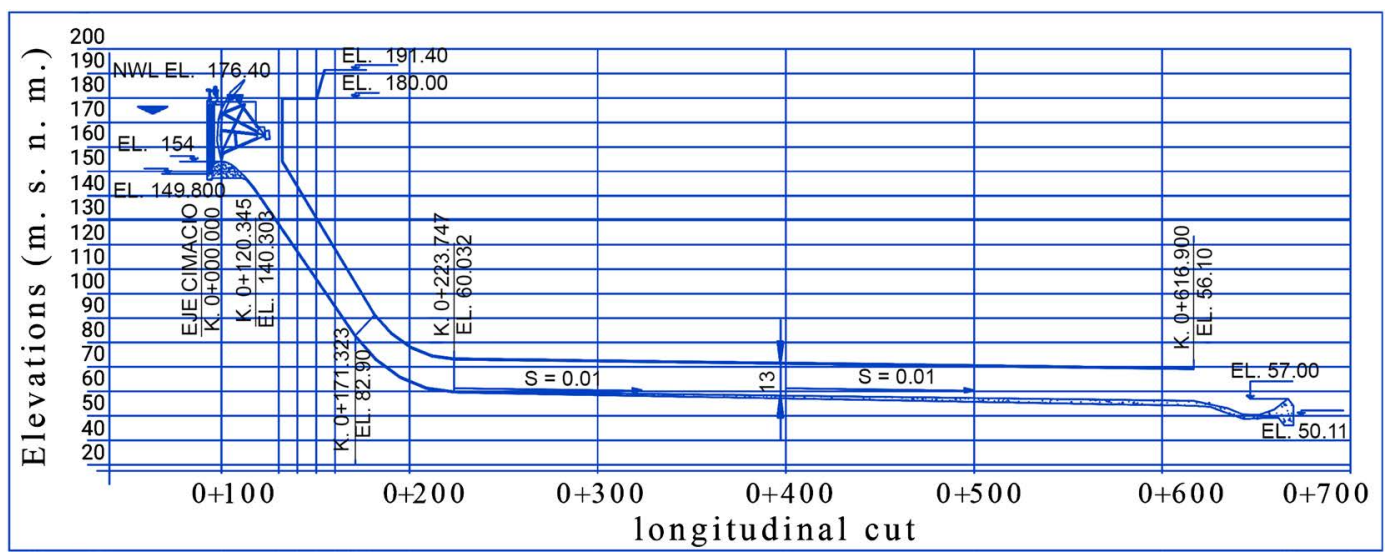

Figure 6. Profile of the $13 \mathrm{~m}$ diameter spillway. 
Table 1. Cavitation indexes along the floor of the tunnel. $Q=2500 \mathrm{~m}^{3} / \mathrm{s}, \quad k=5 \mathrm{~mm}$ $(n=0.017), \quad h_{v}=-9.75 \mathrm{~m}, \quad r_{\text {codo }}=71.50 \mathrm{~m}$.

\begin{tabular}{cccccccccccc}
\hline$x(m)$ & $h(m)$ & $d$ & $h_{p 1}$ & $\frac{d}{g} \frac{V^{2}}{r}$ & $h_{p}$ & $\begin{array}{c}x / k \\
\left(10^{-3}\right)\end{array}$ & $\frac{V_{K}}{\sqrt{2 g h}}$ & $\frac{V_{K}^{2}}{2 g}$ & $\sigma_{k}$ & $\sigma_{k p}$ & $F r$ \\
\hline 20 & 9.0 & 6.40 & 4.25 & 0.0 & 4.25 & 4.0 & 0.428 & 1.65 & 8.49 & 8.49 & 2.60 \\
40 & 20.0 & 6.40 & 4.25 & 0.0 & 4.25 & 8.0 & 0.398 & 3.16 & 4.44 & 4.44 & 2.96 \\
60 & 34.5 & 6.40 & 4.25 & 0.0 & 4.25 & 12.0 & 0.382 & 5.03 & 2.78 & 2.78 & 3.36 \\
80 & 49.5 & 6.40 & 4.25 & 0.0 & 4.25 & 16.0 & 0.372 & 6.86 & 2.04 & 2.04 & 4.04 \\
100 & 55.0 & 6.60 & 4.50 & $12.0 *$ & 16.50 & 20.0 & 0.364 & 8.60 & 3.06 & 2.33 & 5.00 \\
120 & 77.5 & 6.70 & 4.90 & 14.8 & 19.70 & 24.0 & 0.357 & 9.89 & 2.98 & 2.26 & 5.45 \\
140 & 85.8 & 6.70 & 5.60 & 16.3 & 21.90 & 28.0 & 0.352 & 10.60 & 2.99 & 2.27 & 5.72 \\
160 & 88.0 & 6.70 & 6.70 & $16.0 *$ & 22.70 & 32.0 & 0.348 & 10.63 & 3.10 & 2.36 & 5.67 \\
180 & 88.0 & 7.25 & 7.25 & 0.0 & 7.25 & 36.0 & 0.344 & 10.43 & 1.72 & 1.31 & 4.32 \\
200 & 88.0 & 7.25 & 7.25 & 0.0 & 7.25 & 40.0 & 0.341 & 10.23 & 1.75 & 1.33 & 4.32 \\
220 & 88.0 & 7.25 & 7.25 & 0.0 & 7.25 & 44.0 & 0.338 & 10.10 & 1.78 & 1.35 & 4.32 \\
240 & 88.0 & 7.25 & 7.25 & 0.0 & 7.25 & 48.0 & 0.335 & 9.87 & 1.82 & 1.38 & 4.32 \\
260 & 88.0 & 7.25 & 7.25 & 0.0 & 7.25 & 52.0 & 0.333 & 9.76 & 1.84 & 1.40 & 4.32 \\
280 & 88.0 & 7.25 & 7.25 & 0.0 & 7.25 & 56.0 & 0.331 & 9.63 & 1.86 & 1.41 & 4.32 \\
300 & 88.0 & 7.25 & 7.25 & 0.0 & 7.25 & 60.0 & 0.329 & 9.55 & 1.88 & 1.43 & 4.32 \\
\hline
\end{tabular}

${ }^{*}$ Values measured in model.

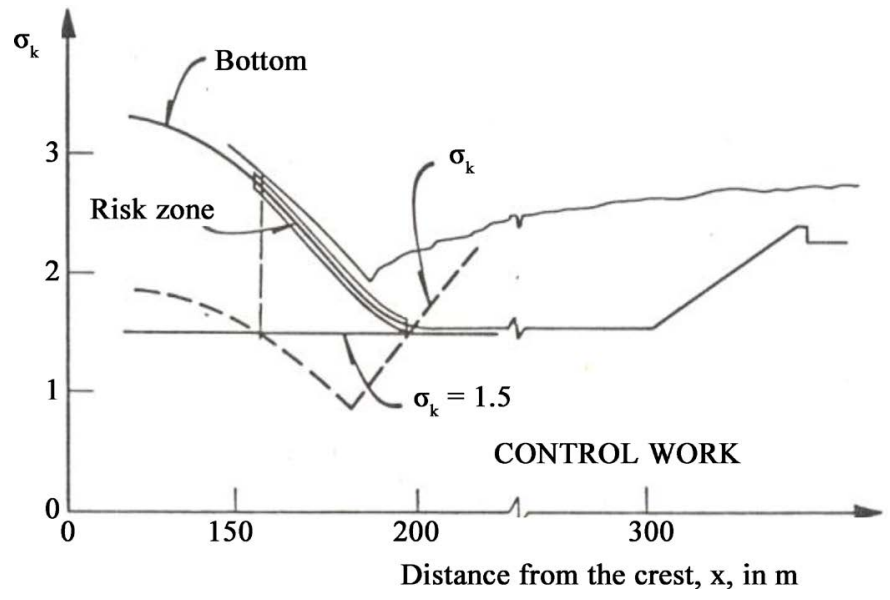

Figure 7. Cavitation risk analysis of the control spillway.

\section{Oroville Dam}

As aforementioned, the 2017 contingency in the Oroville Dam in the state of California (US), is used as an example to demonstrate the critical importance of the problem.

Oroville Dam is a recent catastrophic example of why, unexplainable, neither during nor after construction was the spillway protected with aerators. This could be the possible reason for the severe damages that the dam suffered which en- 
dangered the population and the environment, while repairs are expected to cost several hundred millions of dollars.

The damage geometry in both Figure 9, and its location, Figure 10, clearly suggest that the damage was due to cavitation. In addition, the relatively wide angle of the triangularly-shaped damage, shown in the left side of the photograph in Figure 9 is a characteristic of damage caused not only due to flow velocity, but also to the tendency of a convex flow that facilitates the presence of cavitation, which is a condition that is also fulfilled in this case.

Interestingly, different examples of opinion related to this situation, given by other committees [14] are shown below in its original version.

"During service spillway operation in February 7, 2017, water injection through both cracks and joints in the chute slab resulted in uplift forces beneath the slab that exceeded the uplift capacity and structural strength of the slab, at a location along the steep section of the chute. The uplifted slab section exposed the underlying poor quality foundation rock at that location to unexpected severe erosion; resulting in removal of additional slab sections and more erosion".

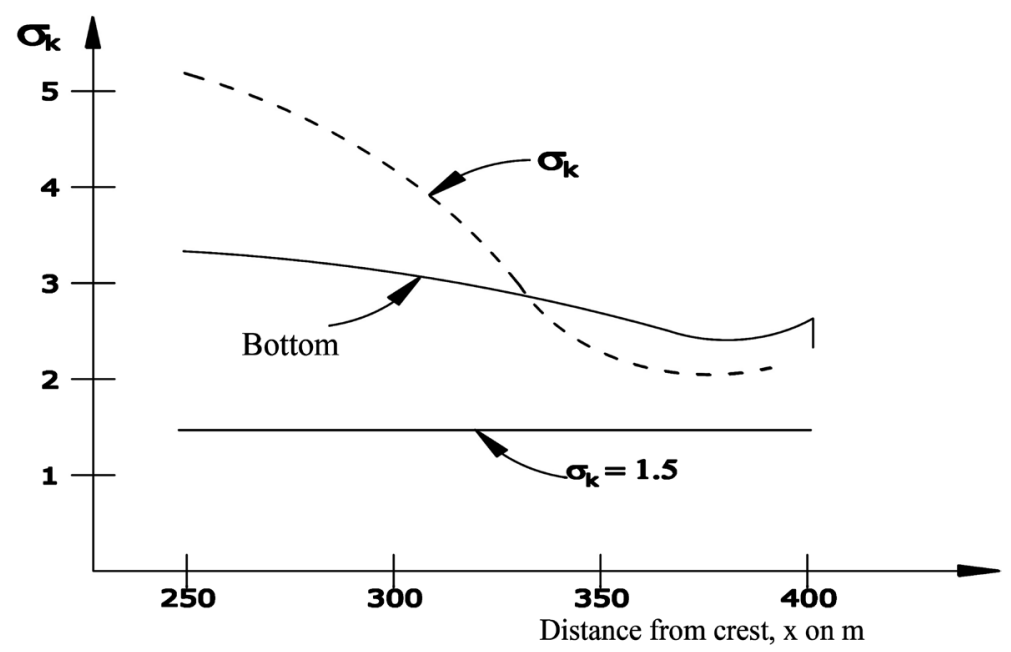

Figure 8. Cavitation risk analysis of the emergency spillway.

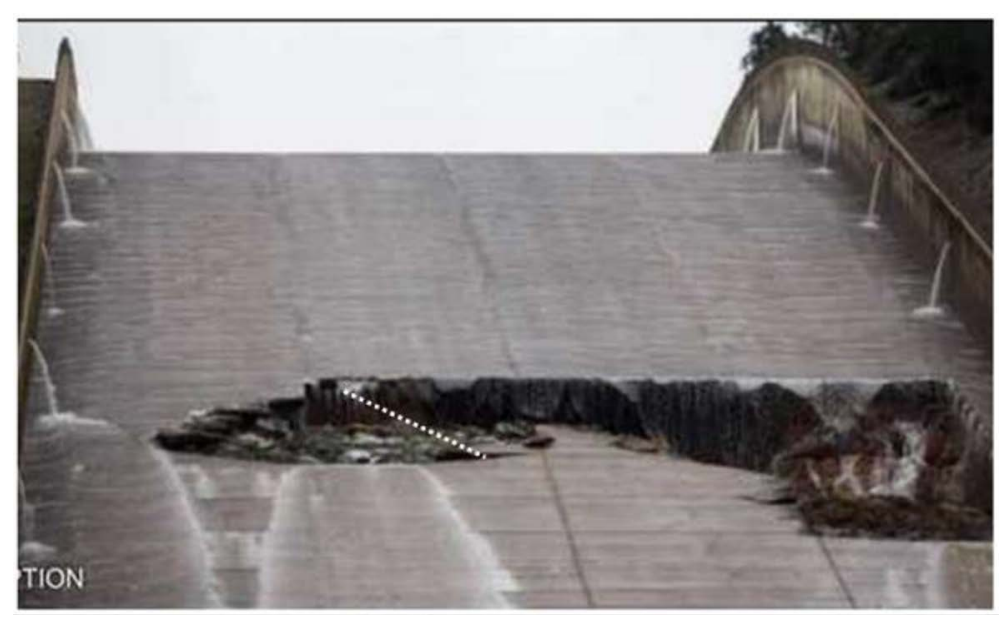

Figure 9. Photograph of the damages geometry in the Oroville Dam spillway. 


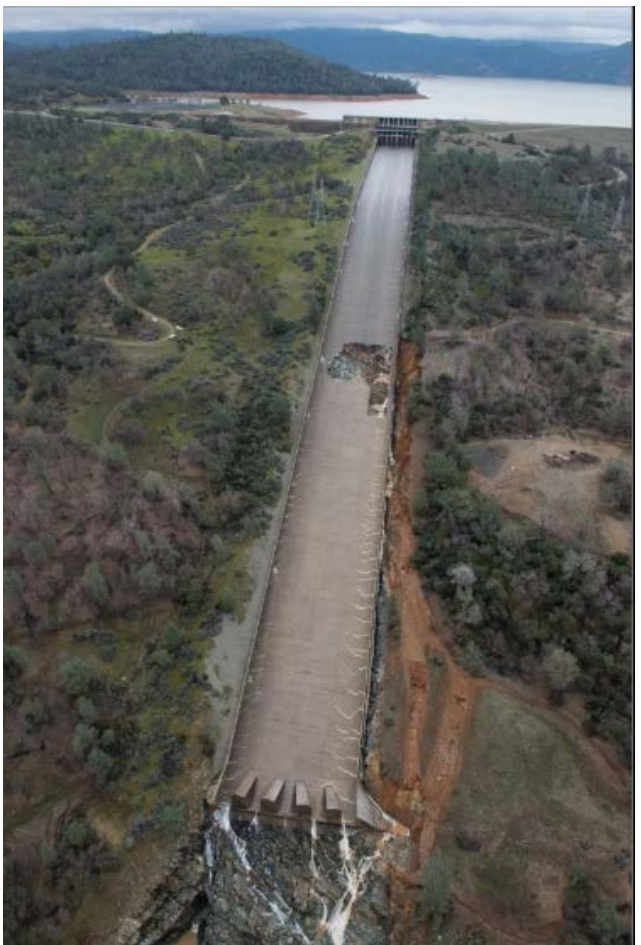

Figure 10. Photograph of the location of the damages in the Oroville Dam spillway.

This shows that there are different opinions about this particular situation, given by very qualified persons that need also to be taken into consideration.

A final comment refers to the fact that there exist many other dams at risk of this type of damage, and it is necessary to identify them and prevent with timely and adequate measures similar catastrophes.

The author dares to predict that if aerators slots or other forms of protection are not placed in Oroville Dam, the same problem will recur in the future.

\section{Conclusion}

The concept of risk of cavitation induced damages should greatly weigh on the design, construction and operation of high-head spillways. This study presents a more rational procedure that takes into consideration the roughness of the surfaces to estimate its possible presence. This recommendation has been validated by years of observations in prototype and it also emphasizes the need to measure in prototype. More importantly, all high-head dams need to be checked because the precipitation expected with climate change puts them at risk of suffering serious damages. Conclusively, Oroville Dam was used in this work as a reference to demonstrate the critical importance of the problem and the serious damages that require prevention measures

\section{Declaration}

\section{Consent for Publication}

The author grants journal of design studies the license of publishing this study. 


\section{Conflicts of Interest}

The author declares no conflicts of interest regarding the publication of this paper.

\section{References}

[1] Echávez, G. (1979) Cavitation in Spillways. Engineering Institute, Mexico City.

[2] Knapp, R.T., Daily, J.W. and Hammitt F.G. (1970) Cavitation. McGraw-Hill, New York.

[3] Arreguín, F. (2005) Water Cavitation and Aeration in Excess Works. Mexican Institute of Water Technology, Mexico City, Mexican Association of Hydraulics.

[4] Chen, W., Li, G., Xie, S. and Yang, K. (2007) Study on Aerators of High Head Spillway Tunnels. Proceedings of the Congress-International Association for Hydraulic Research, Venice, Italy, p. 685.

[5] Echávez, G. (2001) Aerator of the Trigomil Dam, Mexico. Water Power and Dam Construction, Wilmington, United Kingdom, 53, 31-32.

[6] Volkart, P. and Chervet, A. (Ed.) (1983) Air Slots for Flow Aeration. ETH: Laboratory of Hydraulics, Hydrology and Glaciology (VAW), Zurich.

[7] Arndt, R.E. and Ippen, A.T. (1968) Rough Surface Effects on Cavitation Inception. Journal of Basic Engineering, 90, 249-261. https://doi.org/10.1115/1.3605086

[8] Ball, J.W. (1963) Construction Finishes and High-Velocity Flow. Journal of the Construction Division, 89, 91-110. https://doi.org/10.1061/JCCEAZ.0000086

[9] Holl, J.W. (1960) The Inception of Cavitation on Isolated Surface Irregularities. Journal of Basic Engineering, 82, 169-183. https://doi.org/10.1115/1.3662508

[10] Echávez, G. (1969) Concrete Erosion Due to High-Velocity Flows. Engineering Faculty, National Autonomous University of Mexico, Mexico City.

[11] Wan, W., Liu, B. and Raza, A. (2018) Numerical Prediction and Risk Analysis of Hydraulic Cavitation Damage in a High-Speed-Flow Spillway. Shock and Vibration, 2018, Article ID: 1817307. https://doi.org/10.1155/2018/1817307

[12] Fadaei-Kermani, E., Barani, G. and Ghaeini-Hessaroeyeh, M. (2016) Numerical Detection of Cavitation Damage on Dam Spillway. Civil Engineering Journal, 2, 484-490. https://doi.org/10.28991/cej-2016-00000051

[13] Aki, S. (1967) Dynamic Characteristic of the Force Acting on the Spillway Chute. Proceedings 12 th IAHR Congress, Fort Collins, Colorado, 163-170.

[14] France, J.W., Dickson, P.A., Rigbey, S.J., Alvi I.A. and Falvey, H.T. (2018) Independent Forensic Team Report Oroville Dam Spillway Incident. Association of State Dam Safety Officials (ASDSO) and the United States Society on Dams (USSD). 